\title{
Circular Ring Open-Ended Monopole Antenna with Strip for WLAN Dual-Band Operations
}

\author{
Joong-Han Yoon*, Member, KIICE \\ Department of Electronics, Silla University, Busan 617-736, Korea
}

\begin{abstract}
A novel design of a simple circular ring with open-ended monopole antenna for wireless local area network (WLAN) applications is proposed in this article. The proposed antenna consists of an open-ended circular ring and 50- $\Omega$ microstrip feed-line. The proposed antenna is capable of generating two separate resonant modes with good impedance-matching conditions. A prototype of the proposed antenna is designed, fabricated, and measured. Acceptable agreement between the measurement and simulation results is achieved. Experimental results show that the proposed antenna has operating bandwidths of 1.99-3.04 GHz and 5.08-6.1 GHz with a return loss of less than $-10 \mathrm{~dB}$, covering the required bandwidths of the 2.4/5.2/5.8-GHz WLAN standards. This is a microstrip antenna for IEEE $802.11 \mathrm{a} / \mathrm{b}$ wireless local area networks applications. Meanwhile, the two-dimensional (2D) radiation patterns and three-dimensional (3D) gain performance of the antenna are also observed and discussed.
\end{abstract}

Index Terms: Circular ring, Dual-band operation, Open-ended circular ring, WLAN antenna

\section{INTRODUCTION}

The rapid advances in the wireless communication industry demand novel designs that can be used in more than one frequency band and that will allow size reduction. Wireless local area networks (WLANs), wireless printers, and the PCMCIA (Personal Computer Memory Card International Association) card, for instance, utilize the 2.4$\mathrm{GHz}$ band. Moreover, major advances have recently been made in WLAN communications, and to meet the IEEE 802.11a, HiperLAN, and 802.11b WLAN standards, many related products have been designed in such a way as to make them capable of dual-band operations in the $2.4 \mathrm{GHz}$ $(2.4-2.484 \mathrm{GHz})$ and the $5.2 / 5.8 \mathrm{GHz}(5.15-5.95 \mathrm{GHz})$ bands.

A demand for dual-band antennas has thus emerged, and consequently, a number of experimental and theoretical studies have been conducted on multiband antennas. With an increase in the popularity of WLAN communication, the demand for a printed monopole antenna designed with a low-profile, light-weight, flush-mounted, and simple structure has increased. Recently, multiband antennas for WLAN applications have been reported [1-11]. Among all these antennas, printed monopole antennas play an important role due to their attractive features of simple structure, low profile, and reasonably good performance. In particular, several studies on the circular ring monopole antenna have been conducted [12-18].

The circular ring, printed monopole antenna [12], and the M-shaped antenna surrounded with a ring monopole [13] for wideband operations have been developed. Further, the band-notched circular ring monopole antenna [14-16], the

Received 07 May 2013, Revised 24 June 2013, Accepted 11 July 2013

*Corresponding Author Joong-Han Yoon (E-mail: jhyoon@silla.ac.kr, Tel:+82-51-999-5875)

Department of Electronics, Silla University, 140 Baegyang-daero 700beon-gil, Sasang-gu, Busan 617-736, Korea.

(c) This is an Open Access article distributed under the terms of the Creative Commons Attribution Non-Commercial License (http://creativecommons.org/li-censes/by$\mathrm{nc} / 3.0 /$ ) which permits unrestricted non-commercial use, distribution, and reproduction in any medium, provided the original work is properly cited. 
coplanar waveguide (CPW) dual ring loop antenna for dualband operation [17], and a ring monopole ultra-wideband (UWB) antenna with band-notched [18] have been proposed.

In this study, a novel circular ring with an open-ended monopole antenna with a strip suited for dual-band WLAN applications was designed. The proposed antenna comprises a circular ring with an open-ended monopole antenna. By appropriately selecting the dimensions of the proposed antenna, we can achieve good dual broadband bandwidth and radiation characteristics suitable for WLAN 2.4/5.2/5.8$\mathrm{GHz}$ operations. The detailed design considerations and experimental results of the proposed monopole antenna for WLAN operation are presented and discussed below.

\section{ANTENNA DESIGN}

Fig. 1 shows the geometry of the proposed WLAN monopole antenna to achieve a dual-band frequency operation. Fig. 1(a) shows the geometry of the conventional circular ring antenna and Fig. 1(b) shows the proposed circular ring open-ended monopole antenna for WLAN applications. In this design, the total size of the substrate was $21.0 \mathrm{~mm} \times 45.0 \mathrm{~mm}\left(W_{1} \times L_{1}\right)$. The radiating element of the proposed antenna, having the dimensions of $21.0 \mathrm{~mm} \times$ $26.2 \mathrm{~mm}\left(W_{1} \times\left(L_{1}-L_{5}\right)\right)$, is a symmetrical circular ring with an open end having a uniform width of $2 \mathrm{~mm}$ for design convenience. A ground plane having the dimensions of $21.0 \mathrm{~mm} \times 18.2 \mathrm{~mm}\left(W_{1} \times L_{5}\right)$ is placed on the other side of the substrate. In this design, $\mathrm{R}_{1}$ denotes the inner radius, $\mathrm{R}_{2}$ represents the outer radius, and the open-ended circular ring $\left(R_{2}-R_{1}\right)$ with a strip provides the resonance of 2.4GHz bands. A $50-\Omega$ microstrip feed-line, $W_{3}=2 \mathrm{~mm}$, is used for feeding the antenna from the bottom edge of the symmetrical circular ring. To obtain good impedance matching for operating frequencies, we introduced a strip measuring $1.5 \mathrm{~mm} \times 4.0 \mathrm{~mm}\left(W_{4} \times L_{3}\right)$ in the open-ended circular ring. The strip is positioned at the top edge of the open end of the circular ring. Further, we introduced another strip measuring $2.0 \mathrm{~mm} \times 2.0 \mathrm{~mm}\left(W_{5} \times L_{4}\right)$ upward at the bottom of the open-ended circular ring. The proposed antenna is fabricated on one side of an inexpensive FR4 substrate with the relative permittivity of 4.4 and a substrate thickness of $1.0 \mathrm{~mm}$. These geometrical parameters of the proposed antenna are optimized using the commercially available simulation software of Ansoft High Frequency Structure Simulator (HFSS) [19]. The block diagram of the antenna design process is given in [11].

\section{A. Effect of the Open-Ended Circular Ring}

Fig. 2 shows the return loss of a conventional circular ring and the open end of the circular ring. In the 2.4- and 5-
$\mathrm{GHz}$ bands, as can be seen in the figure, the impedance bandwidth and return loss characteristics varied slightly. It can be seen in the figure, however, that in the case of the open-ended circular ring antenna with a strip, the return loss characteristics were better than those in the case of the conventional circular ring antenna. Thus, to design an optimal dual-band WLAN operation, we introduce an openended circular ring antenna with a strip.

\section{B. Effect of the Ground Plane}

Fig. 3 shows the return loss for different values of the ground plane $\left(W_{1}\right)$. In the $2.4-$ and $5-\mathrm{GHz}$ bands, it can be seen in the figure that the impedance bandwidth and return loss characteristics changed slightly when $W_{1}$ was varied from 19.0 to $25.0 \mathrm{~mm}$. It can be seen in the figure, however, that when $W_{1}$ was $21.0 \mathrm{~mm}$, the impedance bandwidth of the return loss was better than that in the other cases $\left(W_{1}=19.0\right.$, 23.0, $25.0 \mathrm{~mm}$ ). Thus, to design an optimal dual-band WLAN operation, $W_{1}$ was set at $21.0 \mathrm{~mm}$.

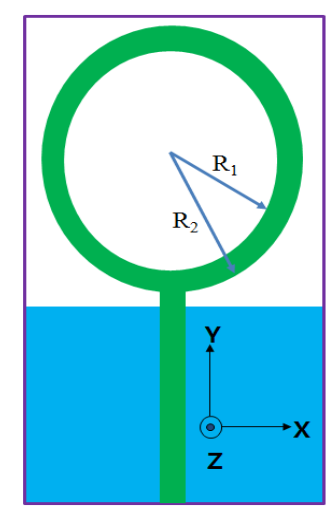

(a)

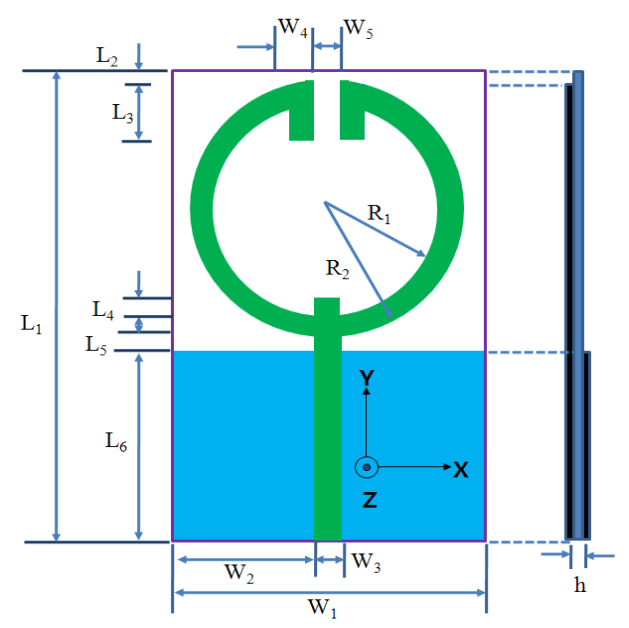

(b)

Fig. 1. Configuration of the microstrip-fed circular ring monopole antenna: (a) conventional and (b) open-ended. 


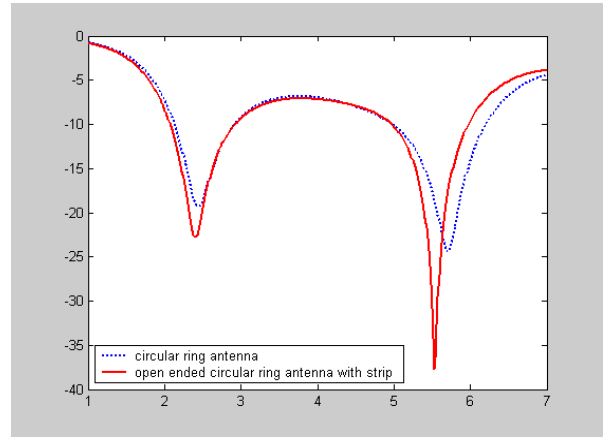

Fig. 2. Simulated return loss of the proposed antenna with and without an open end in the circular ring.

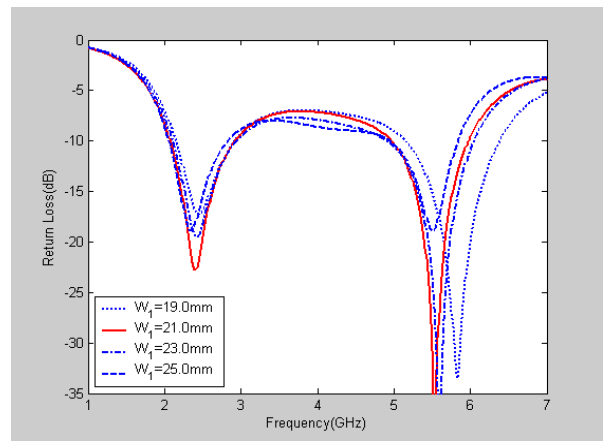

Fig. 3. Simulated return loss of the proposed antenna with different values of $W_{1}$

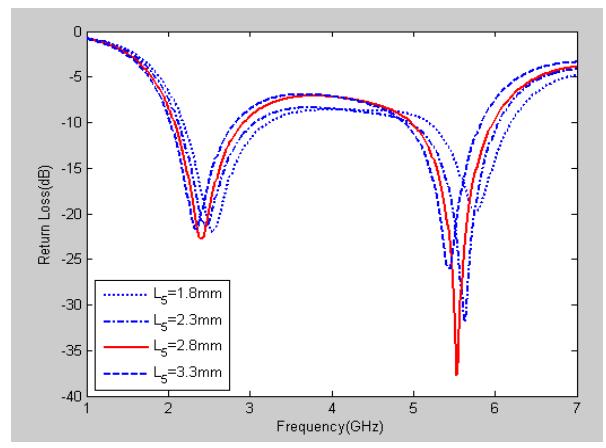

Fig. 4. Simulated return loss of the proposed antenna with different values of $L_{5}$.

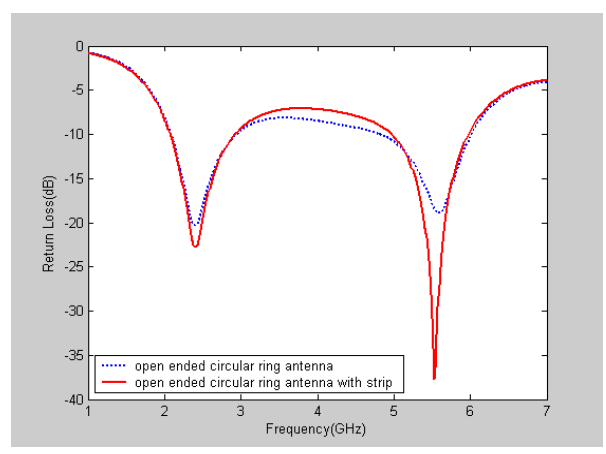

Fig. 5. Simulated return loss of the proposed antenna with and without a strip in the open-ended circular ring antenna $\left(L_{4}\right)$.

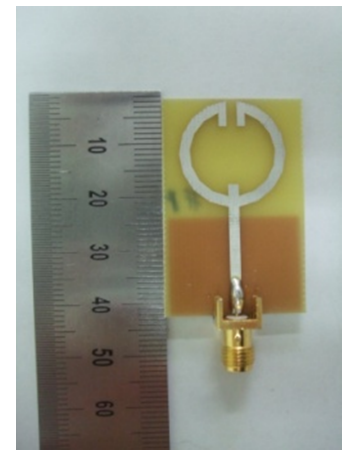

(a)

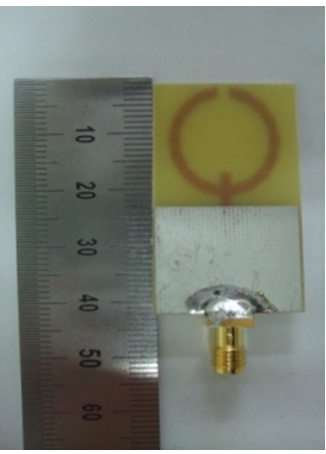

(b)
Fig. 6. Prototype of the proposed dual-band antenna: (a) front view and (b) back view

\section{Effect of the Gap between the Ground Plane and the Circular Ring Open-Ended Antenna, $L_{5}$}

Fig. 4 shows the return loss for different gaps $\left(L_{5}\right)$ between the circular ring-shaped antenna and the ground plane. In the 2.4- and 5-GHz bands, it can be seen in the figure that the impedance bandwidth and return loss characteristics changed slightly, when $L_{4}$ was varied from 1.8 to $3.3 \mathrm{~mm}$. It can be seen in the figure, however, that when $L_{5}$ was $2.8 \mathrm{~mm}$, the impedance bandwidth of the return loss was better than that of the other cases $\left(L_{5}=1.8\right.$, $2.8,3.3 \mathrm{~mm})$. Thus, to design an optimal dual-band WLAN operation, $L_{5}$ was set at $2.2 \mathrm{~mm}$.

\section{Effect of the Strip in the Open-Ended Circular Ring}

A strip was introduced into the open-ended circular ring to alter the input impedance characteristics. Fig. 5 shows the return loss with and without a strip in the open-ended circular ring. The impedance bandwidth and return loss characteristics worsened when there was no strip in the open-ended circular ring. This indicates that the strip plays an important role in the impedance matching of the proposed antenna. The optimal values of the strip width $\left(W_{4}\right)$ and length $\left(L_{3}\right)$ were determined. Thus, to design a good dual-band WLAN operation, $W_{4}$ was set at $2.0 \mathrm{~mm}$ and $L_{3}$ was set at $2.0 \mathrm{~mm}$.

The proposed antenna structure has several design parameters that can handle the resistance and the reactance of the antenna input impedance. As such, the dimensions of the proposed antenna were set as follows: $R_{1}=8.0 \mathrm{~mm} ; R_{2}=$ $10.0 \mathrm{~mm} ; W_{1}=25.0 \mathrm{~mm} ; W_{2}=11.5 \mathrm{~mm} ; W_{3}=2.0 \mathrm{~mm} ; W_{4}$ $=1.5 \mathrm{~mm} ; W_{5}=2.0 \mathrm{~mm} ; L_{1}=40.0 \mathrm{~mm} ; L_{2}=5.0 \mathrm{~mm} ; L_{3}=$ $4.0 \mathrm{~mm} ; L_{4}=2.2 \mathrm{~mm} ; L_{5}=2.8 \mathrm{~mm} ; L_{6}=18.2 \mathrm{~mm}$; and $\mathrm{h}=$ $1.0 \mathrm{~mm}$. On the basis of the abovementioned design 
dimensions, the proposed compact antenna was constructed and studied. A prototype of the proposed antenna was fabricated with the aforementioned design parameters and is shown in Fig. 6(a) and (b).

\section{MEASUREMENT AND RESULT}

A prototype of the optimized antennas was fabricated and measured for the return loss, radiation pattern, and gain. Fig. 7 shows the measured and simulated return loss of the proposed antenna for a multioperation wireless communication application. The frequency response of the return loss of the proposed antenna was measured using an Anritsu MS4644A vector network analyzer at Silla University. The results demonstrate that simulated data and measured data have a generally acceptable agreement. It can be seen in the figure that there is a slight difference between the simulation and the measurement results. This is probably due to the influence of the cable connected to the fabricated antenna in the measurement procedure. Further, this discrepancy between the measurement data and the simulation results could be due to the effect of the SMA port. To confirm the accurate return loss characteristics of the designed antenna, it is recommended that the manufacturing and measurement process be performed carefully. There are two resonant modes that are excited at approximately 2.425 and 5.665 $\mathrm{GHz}$, respectively, with wide impedance band-widths. The lowest resonant mode has a $10-\mathrm{dB}$ impedance bandwidth of $1,050 \mathrm{MHz}(1.99-3.04 \mathrm{GHz})$, which covers the $2.4-\mathrm{GHz}$ WLAN bands. The second resonant mode has an impedance bandwidth of 1,020 MHz (5.08-6.1 GHz), which satisfies the required bandwidth of the 5.2/5.8-GHz WLAN bands. Clearly, the design prototype of the proposed antenna has sufficient bandwidth to cover the needs of the 2.4- and 5GHz WLAN bands (2.4-2.484 GHz and 5.15-5.825 GHz, respectively).

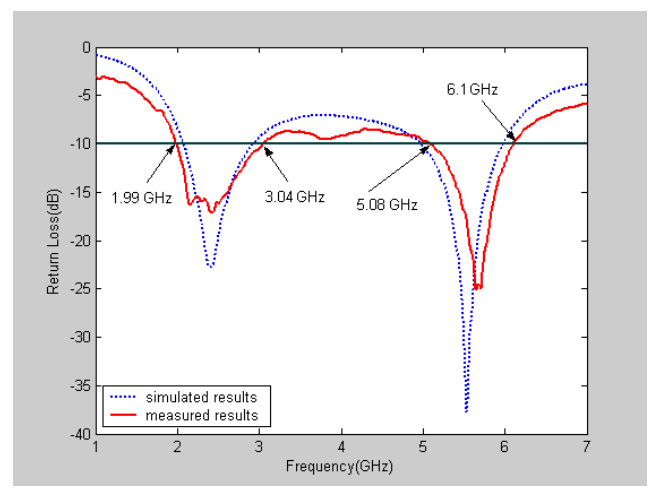

Fig. 7. Simulated and measured return loss vs. the frequencies of the proposed antenna.

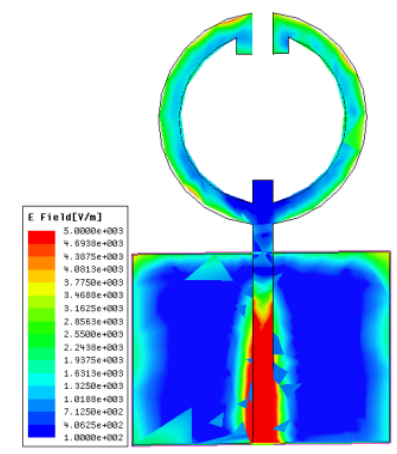

(a)

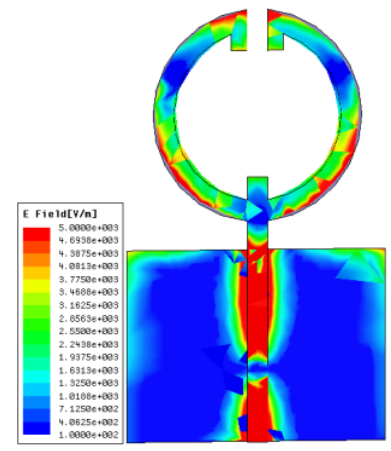

(b)
Fig. 8. Surface current distributions at (a) $2.42 \mathrm{GHz}$ and (b) $5.63 \mathrm{GHz}$.

Theoretically, HFSS was used to evaluate and verify the two resonant frequencies of 2.42 and $5.63 \mathrm{GHz}$, which mainly depended on the lengths of the open-ended circular ring. Fig. 8(a) and (b) show the surface current density excitations along the open-ended circular ring antenna in the cases of the two resonant frequencies of 2.42 and $5.63 \mathrm{GHz}$, respectively. As shown in Fig. 8(a), the 2.4-GHz band surface current density excitations along the open-ended circular ring was observed when the resonant frequency was $2.42 \mathrm{GHz}$. Thus, it is implied that the excitation of the 2.4$\mathrm{GHz}$ bands is mainly contributed by the open-ended circular ring. As shown in Fig. 8(b), however, larger surface current density excitations flowed along the bottom of the openended circular ring antenna when the resonant frequency was $5.575 \mathrm{GHz}$. As we can see in this figure, the $5-\mathrm{GHz}$ band is more strongly excited than the $2.4-\mathrm{GHz}$ band in the case of the open-ended circular ring antenna.

Fig. 9 shows the measured 2D far-field radiation patterns in the E-plane (x-z plane) and the H-plane (y-z plane) at the 2.4- and 2.45-GHz bands. Fig. 10 shows the measured $2 \mathrm{D}$ far-field radiation patterns in the E-plane (x-z plane) and the H-plane (y-z plane) at the 5.3- and 5.7-GHz bands. From the perspective of these radiation patterns, the proposed antenna displays omni-directional radiation characteristics in the $\mathrm{H}$ plane and monopole-like radiation pattern characteristics in the E-plane at the considered frequencies.

Fig. 11(a) and (b) show the 3D measured antenna peak and the average gain for the frequencies across the 2.4- and 5-GHz bands. The 2.4-GHz band had an antenna peak gain level of approximately 1.07 to $1.58 \mathrm{dBi}$ in Fig. 11(a), and the $5-\mathrm{GHz}$ band, approximately 0.02 to $2.93 \mathrm{dBi}$ in Fig. 11(b). 


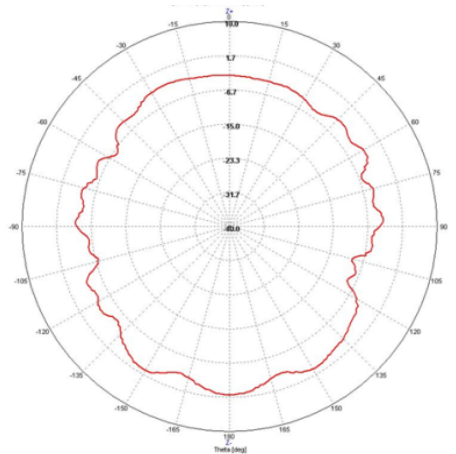

(a)

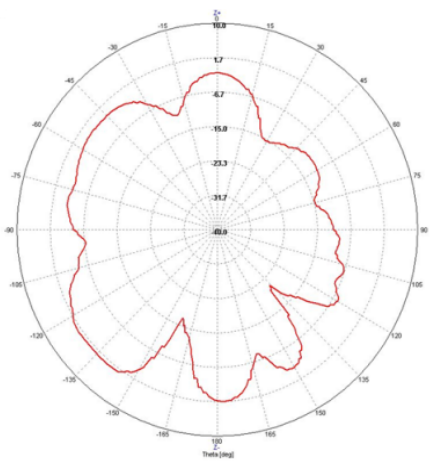

(b)

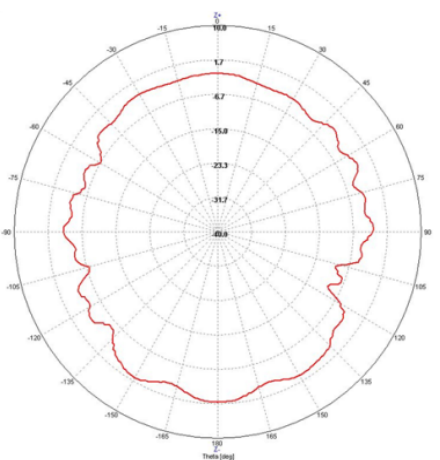

(c)

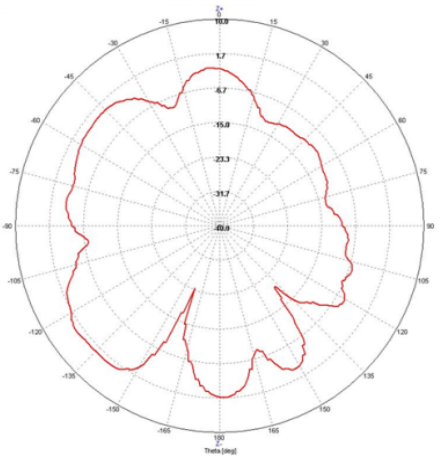

(d)

Fig. 9. Radiation patterns of the proposed antenna at 2.4 and $2.45 \mathrm{GHz}$ in the E-plane and the H-plane: (a) $2.4 \mathrm{GHz}$ (E-plane), (b) $2.4 \mathrm{GHz}(\mathrm{H}$ plane), (c) $2.45 \mathrm{GHz}$ (E-plane), and (d) $2.45 \mathrm{GHz}$ (H-plane).

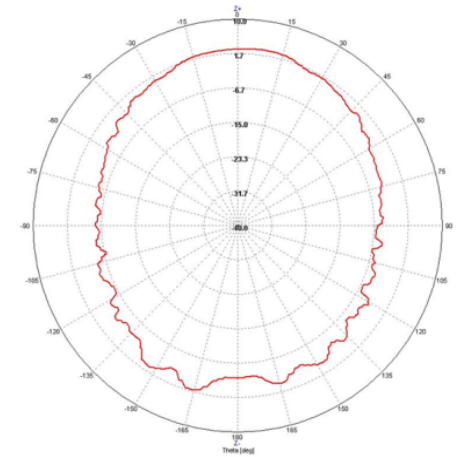

(a)

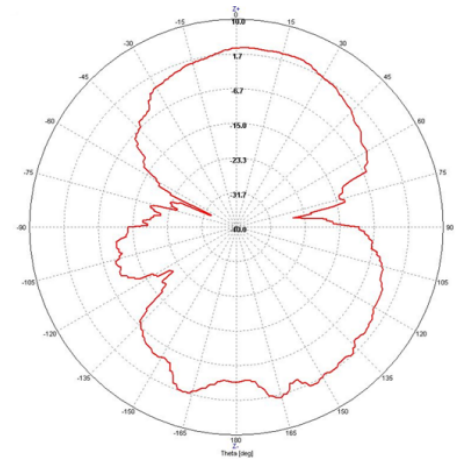

(b)

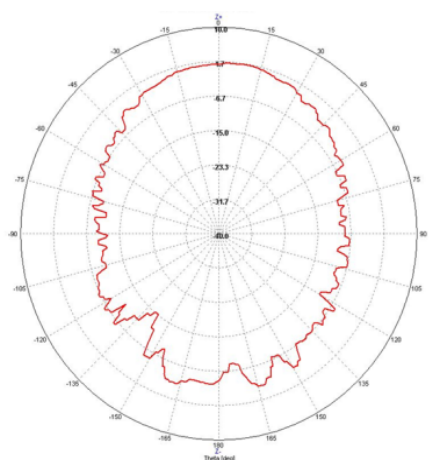

(c)

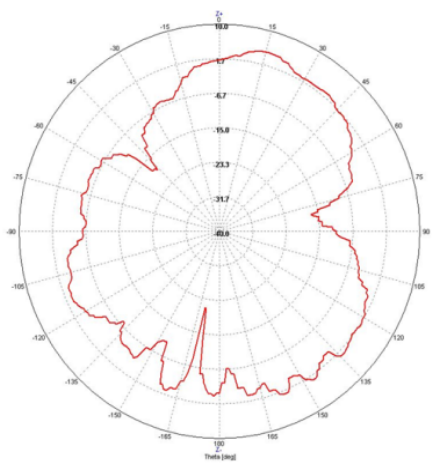

(d)

Fig. 10. Radiation patterns of the proposed antenna at 5.3 and $5.7 \mathrm{GHz}$ in the E-plane and the H-plane: (a) $5.3 \mathrm{GHz}$ (E-plane), (b) $5.3 \mathrm{GHz}(\mathrm{H}$ plane), (c) $5.7 \mathrm{GHz}$ (E-plane), and (d) $5.7 \mathrm{GHz}$ (H-plane). 


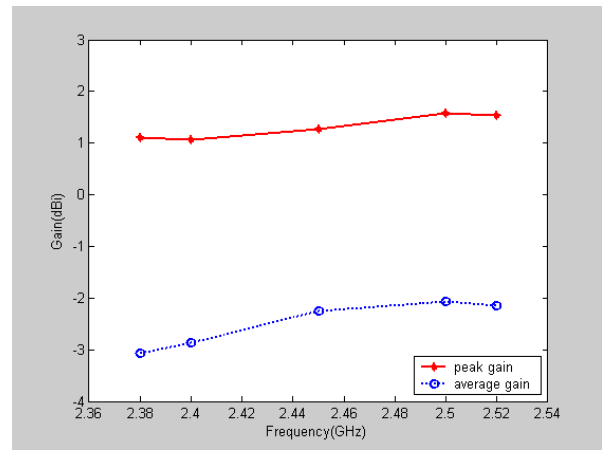

(a)

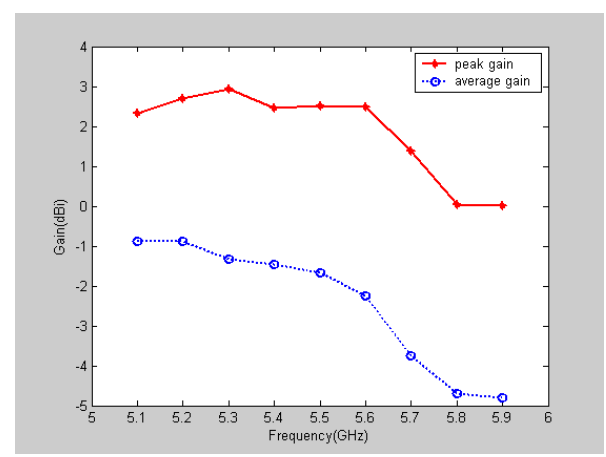

(b)

Fig. 11. Measured antenna peak and average gains for the following operating frequencies: (a) $2.4-\mathrm{GHz}$ band and (b) $5-\mathrm{GHz}$ band.

The 2.4-GHz band had an antenna average gain level of approximately -3.07 to $-2.06 \mathrm{dBi}$ in Fig. 11(a), and the 5$\mathrm{GHz}$ band, approximately -4.8 to $-0.87 \mathrm{dBi}$ in Fig. 11(b). The $2 \mathrm{D}$ antenna gain had a peak value of $1.58 \mathrm{dBi}$ at 2.5 GHz. At $5.3 \mathrm{GHz}$, the 2D maximum peak gain was $2.93 \mathrm{dBi}$ and at $5.6 \mathrm{GHz}, 2.48 \mathrm{dBi}$. As a result, the gain of the proposed antenna within the operating bands satisfies the requirements for WLAN systems.

\section{CONCLUSION}

In this article, we proposed a simple circular ring openended monopole antenna for dual-band WLAN operations. With the use of the open-ended circular ring, the impedance bandwidth needed to meet the requirements of WLAN in the 2.4/5.2/5.8-GHz bands was achieved. Various parameters of the proposed antenna were optimized via simulation (HFSS) and tested. Parametric studies of the proposed antenna were conducted and the mechanisms of the dual-band operation were discussed. This proposed monopole antenna had -10 $\mathrm{dB}$ impedance bandwidths of approximately 1,020 and $1,050 \mathrm{MHz}(1.99-3.04$ and $5.08-6.1 \mathrm{GHz})$ or approximately $10.44 \%$ and $18.25 \%$. The experiment results showed that good impedance matching was achieved. Omni-directional radiation pattern characteristics for frequencies over the
WLAN bands were also obtained for the proposed antenna. The proposed antenna's measured peak gain varied between 1.07 and $1.58 \mathrm{dBi}$ in the case of the $2.4-\mathrm{GHz}$ band and 0.02 and $2.93 \mathrm{dBi}$ in the case of the $5-\mathrm{GHz}$ band. Because of its low cost, light weight, and compact size, the proposed antenna is very suitable for WLAN applications.

\section{ACKNOWLEDGMENTS}

The authors would like to thank Dr. D. S. An, Director of Maxwave Corporation in Korea for assistance in the measurement of antenna radiation patterns.

\section{REFERENCES}

[ 1 ] Y. Liu, Z. Niu, and X. Wang, "Dual band H-shaped slot antenna for 2.4 and $5 \mathrm{GHz}$ wireless communication," Microwave and Optical Technology Letters, vol. 52, no. 4, pp. 957-959, 2010.

[2 ] S. I. Park, "Design of planar-type modified folded loop antennas," International Journal of KIMICS, vol. 8, no. 5, pp. 489-492, 2010.

[ 3 ] S. W. Su and F. S. Chang, "Compact, printed mobile-unit antenna for $2.4 \mathrm{GHz}$ and $5 \mathrm{GHz}$ WLAN applications," Microwave and Optical Technology Letters, vol. 52, no. 12, pp. 2648-2653, 2010.

[4] M. Harmouzi and M. Essaaidi, "A novel compact dual-band antenna for IEEE $802.11 \mathrm{a} / \mathrm{b} / \mathrm{g} / \mathrm{n}$ WLAN," Microwave and Optical Technology Letters, vol. 53, no. 2, pp. 315-317, 2011.

[ 5 ] W. S. Chen, B. Y. Lee, and P. Y. Chang, “A compact and small printed monopole antenna for WLAN applications," Microwave and Optical Technology Letters, vol. 53, no. 7, pp. 1518-1522, 2011.

[6] W. C. Liu and Y. Dai, "A dual-band shorted monopole antenna for WLAN-band applications," Microwave and Optical Technology Letters, vol. 53, no. 9, pp. 2142-2145, 2011.

[ 7 ] N. Zang, Y. J. Wang, and X. W. Shi, "Compact dual-band printed dipole antenna with parallel-winding lines and tapered structure for WLAN applications," Microwave and Optical Technology Letters, vol. 53, no. 11, pp. 2492-2494, 2011.

[ 8 ] S. A. Rahim, Z. Nor, N. M. Jizat, M. Sabran, and M. F. Jamlos, "Dual-band printed monopole slot antenna with combination of Lslot and ARM slot for WLAN application," Microwave and Optical Technology Letters, vol. 53, no. 11, pp. 2668-2673, 2011.

[9] Y. Seo, J. Jung, H. Lee, and Y. Lim, "Modified dual monopole antenna for WLAN operation," Microwave and Optical Technology Letters, vol. 53, no. 12, pp. 2768-2770, 2011.

[10] W. C. Liu and Y. L. Chen, "Compact strip-monopole antenna for WLAN-band USB dongle applications," Electronics Letters, vol. 47, no. 8, pp. 479-480, 2011.

[11] J. H. Yoon, "Rectangular ring open-ended monopole antenna with inverted L-strip for WLAN dual-band operations," Journal of Information and Communication Convergence Engineering, vol. 10, no. 4, pp. 321-328, 2012. 
[12] J. Liang, C. C. Chiau, X. Chen, and C. G. Parini, "Printed circular ring monopole antennas," Microwave and Optical Technology Letters, vol. 45, no. 5, pp. 372-375, 2005.

[13] M. R. Aghda, M. R. Kamarudin, and H. U. Iddi, "M-shape surrounded with ring patch wideband monopole printed antenna," Microwave and Optical Technology Letters, vol. 54, no. 2, pp. 482-486, 2012.

[14] F. J. Wang, X. X. Yang, J. S. Zhang, G. P. Gao, and J. X. Xiao, “A band-notched ring monopole antenna," Microwave and Optical Technology Letters, vol. 50, no. 7, pp. 1882-1884, 2008.

[15] J. X. Xiao, M. F. Wang, and G. J. Li, "A printed circular-ring monopole antenna with band-notched feature for UWB application," Microwave and Optical Technology Letters, vol. 52, no. 4, pp. 827-830, 2010
[16] L. Liu, S. W. Cheung, R. Azim, and M. T. Islam, "A compact circular-ring antenna for ultra-wideband applications," Microwave and Optical Technology Letters, vol. 53, no. 4, pp. 22832288, 2011.

[17] H. Lee and Y. M. Lim, "Printed dual ring loop antenna for widedual-frequency band of wireless applications," Microwave and Optical Technology Letters, vol. 54, no. 5, pp. 1317-1318, 2012.

[18] M. K. Yang, G. P. Gao, S. F. Niu, and J. S. Zhang, "Study of a compact ring monopole UWB antenna with band-notched characteristic," Microwave and Optical Technology Letters, vol. 54, no. 10, pp. 2387-2392, 2012.

[19] ANSYS HFSS [Internet], Available from: http://www.ansys.com/ Products/Simulation+Technology/Electromagnetics/Signal+Integri ty/ANSYS+HFSS.

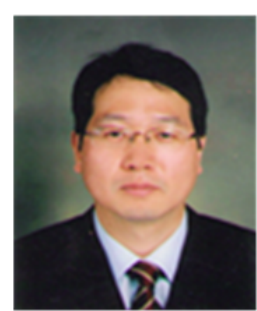

\section{Joong-Han Yoon}

received his B.S., M.S., and Ph.D. degrees in electronics engineering from Inha University, Incheon, South Korea, in 1994, 1996, and 2003, respectively. From 2003, he was a postdoctoral researcher at Inha University. From November 2004 to October 2005, he was a postdoctoral researcher at Yokohama National University, Yokohama, Japan. From November 2005 to August 2008, he was a Senior Engineer at Samsung Electro-Mechanics, Suwon, Korea. Since September 2008, he has been a faculty member of the Department of Electronics Engineering, Silla University, Busan, South Korea. His research interests include mobile antennas, RFID, and digital radar. 